\title{
The impact of ride hailing on parking (and vice versa)
}

\author{
Alejandro Henao \\ National Renewable Energy Laboratory \\ alejandro.henao@nrel.gov
}

\author{
Wesley E. Marshall \\ University of Colorado Denver \\ wesley.marshall@ucdenver.edu
}

\begin{abstract}
Investigating emerging transportation services is critical to forecasting mode choice and providing appropriate infrastructure. One such infrastructure is parking, as parking demand may shift with the availability of ride-hailing services. This study uses ethnographic methods-complemented with passenger surveys collected when driving for Uber and Lyft in the Denver, Colorado, region-to gather quantitative and qualitative data on ride-hailing and analyze the impacts of ridehailing on parking, including changes in parking demand and parking as a reason to deter driving. The study also examines relationships between parking time and cost. This includes building a classification tree-based model to predict the replaced driving trips as a function of car ownership, destination land type, parking stress, and demographics.

The results suggest that: i) ride-hailing is replacing driving trips and could reduce parking demand, particularly at land uses such as airports, event venues, restaurants, and bars; ii) parking stress is a key reason respondents chose not to drive; and iii) respondents are generally willing to pay more for reduced parking time and distance. Conversely, parking supply, time, and cost can all influence travel behavior and ridehailing use. This study provides insight into potential benefits and disadvantages of ride-hailing as related to parking.
\end{abstract}

Keywords: Ride-hailing, ridesourcing, TNC, Uber, Lyft, parking, curb space management

\section{Introduction}

This paper focuses on the impacts of ride-hailing on parking, looking at the bi-directional relationship between these two topics. In other words, does ride-hailing contribute to changes in parking demand? On the other hand, how does parking stress (i.e., availability, time, and cost) deter driving trips and encourage ride-hailing use? If ride-hailing replaces driving trips, we should theoretically reduce parking supply, as more people can access destinations without requiring an accompanying parking space. In turn, this could facilitate re-allocating parking infrastructure to other needs and land uses.

Obtaining data for independent academic research from ride-hailing companies such as Uber and Lyft is extremely difficult (Levitt, 2016). Even when these companies agree to share data, the data is often not adequate for research purposes (Vaccaro, 2016) or does not contain the required information

Copyright 2019 Alejandro Henao \& Wesley E. Marshall http://dx.doi.org/10.5198/jtlu.2019.1392

ISSN: 1938-7849 | Licensed under the Creative Commons Attribution - Noncommercial License 4.0

The Journal of Transport and Land Use is the official journal of the World Society for Transport and Land Use (WSTLUR) and is published and sponsored by the University of Minnesota Center for Transportation Studies.

\section{Article history:}

Received: March 5, 2018

Received in revised form:

Accepted: December 26, 2018

Available online: February 18, 2019 
to answer even the most basic research questions. For this study, one of the authors collected data by serving as an independent-contractor driving for both Uber and Lyft. This type of research combines ethnography with additional elements—interviews and technology-based data—in order to facilitate both quantitative and qualitative analysis.

We designed the study to look specifically at ride-hailing trips that otherwise would have needed parking (e.g., if passengers would have driven their own car or rented a vehicle). For instance, our onboard passenger survey asked passengers about: i) driving mode replacement in terms of what mode they would have used if not for Uber or Lyft; and ii) parking as a stated reason to use ride-hailing instead of another mode. After dropping off the passenger, the driver pretended he needed to park to estimate "cruising to park" time, parking cost, and the estimated walking time from the parking spot to the final destination. This combination of data allowed us to assess the relative shift in parking demand and the contribution of parking as a reason of why someone decides to use ride-hailing.

This paper is divided into the following five sections: literature review, data, methods, results, and discussion/conclusions. The literature review section contains previous research studies relevant to ridehailing and parking. In the data section, we describe in more detail the study design and data collection. The methods section explains the classification tree-model analysis. We follow with the results section and finalize the paper with conclusions and a discussion of the bi-directional implications of ride-hailing and parking in the context of transportation and land use.

\section{$2 \quad$ Literature review}

We are beginning to see an increase in academic research related to ride-hailing services. For this study, we focus on the literature specific to ride-hailing and parking-related outcomes. Since parking is affected when ride-hailing replaces driving, we also consider how passengers are choosing this service as a new means of travel and what transportation modes are being replaced. We then review the literature on parking availability, time, and cost with respect to predicting (encouraging or deterring) driving mode choice.

We use ethnography as the main data collection method to examine travel behavior of the population using ride-hailing in the Denver metro area. Ethnography, as the representation of empirical data on humans, has been explored thoroughly in biological, social, and cultural studies from anthropology, and more recently has become widely used in social science (Brewer, 2000; Lewis, 2015). While the main method of ethnography studies is participant observation, ethnographers also conduct interviews and surveys (O'Reilly, 2012). While ethnographic studies are not common in transportation science, it offers valuable insights for understanding phenomena by researchers delving in and studying a topic from a participatory perspective. Specific to our research, we were able to learn about ride-hailing from the driver interacting with passengers and collecting both quantitative and qualitative data. Such data would have been difficult to acquire without becoming a driver for Uber and Lyft.

Regarding ride-hailing research, one of the first case studies looking at passenger travel behavior changes used an intercept survey to compare taxis, transit, and ride-hailing services in San Francisco (Rayle, Dai, Chan, Cervero, \& Shaheen, 2016). While this study was conducted at an early stage of ridehailing entrance in 2014, participants stated that ride-hailing both substitutes and complements public transit, walking, and biking. Overall, $7 \%$ of survey respondents stated that they would have driven, and $8 \%$ would not have traveled (i.e., induced travel effect) if ride-hailing services were not available.

A case study in Austin, Texas, surveyed people to examine how their habits changed after Uber and Lyft left the city due to a local law change requiring driver fingerprinting and background checks. After Uber and Lyft ceased operation, the researchers found that $41 \%$ of respondents shifted to a personal 
vehicle while 3\% shifted to public transit. Additionally, 9\% of respondents stated that they purchased a vehicle after the ride-hailing companies left (Hampshire, Simek, Fabusuyi, Di, \& Chen, 2017).

More recently, a report surveying over 4,000 adults in major U.S. metropolitan areas found that $21 \%$ of adults personally use ride-hailing services. Of those ride-hailing users, $39 \%$ were substituting driving, $15 \%$ public transportation, $23 \%$ bike or walk, and $22 \%$ would not have made the trip (Clewlow $\&$ Mishra, 2017). More relevant to this study, the same report found that $37 \%$ of urban ride-hailing users cite parking issues as their top reason to do so. Second on the list was avoiding driving when drinking (33\% of ride-hailing users).

Regarding parking, several studies suggest that parking availability (Guo, 2013; Weinberger, 2012; Weinberger, Seaman, \& Johnson, 2009) and cost (Hess, 2001; Wilson \& Shoup, 1990; Wilson, 1992) are significantly associated with car ownership and mode choice. The higher the parking supply and the lower the cost to park, the higher the chance of someone owning a car and/or choosing to drive as the mode of transportation. Parking also poses a problem in terms of cruising for a parking space at destination locations and the related traffic congestion (Brooke, Ison, \& Quddus, 2014; Shoup, 2006).

Recent studies suggest that parking revenues have been declining due to the increase in ride-hailing use in urban areas (Morris, 2018; Steele, 2018). Airports are also experiencing a similar trend with changes in ground transportation revenue from parking and other services (Mandle \& Box, 2017; Zipkin, 2017). More recently, a study of medium to major airports found that parking revenues peaked one to two years after ride-hailing companies started their service, and a steady decline in parking revenues followed since then (Henao, Sperling, Garikapati, Hou, \& Young, 2018). This has caused some airports to reconsider parking needs. Developers are similarly beginning to rethink parking, and transportation professionals continue to suggest a future decline in parking demand as new services and automated vehicles come into place.

While ride-hailing may negatively impact transportation with increased deadheading (drivers circulating around without passengers), vehicle miles traveled, congestion, and substituting from more sustainable modes such as walking, biking, and public transportation (Clewlow \& Mishra, 2017; Henao, 2017; Henao \& Marshall, 2018), a positive impact might be found in parking. Parking, with respect to ride-hailing, presents an opportunity to: i) lower parking generation rates, ii) reduce zoning requirements or eliminate minimums with some land uses, and iii) replace parking spaces with different land uses and economic development opportunities. Changes with ride-hailing and parking could also reduce car ownership and personal driving trips.

The literature on ride-hailing remains limited, in part due to the novelty and lack of open data on these services. Thus, it is difficult for cities and transportation agencies to know what to do when it comes to emerging services such as ride-hailing. This study aims to begin filling this gap in the literature by looking in more detail at changes with respect to parking.

\section{Data}

Realizing the lack of available data from companies such as Uber and Lyft, we decided to collect the data ourselves by one of us signing up as a driver for both companies. By doing this, we were able to gain access to exclusive data and interact directly with passengers. To our knowledge, this is the first independent research that implements an ethnographic approach for ride-hailing data collection with passengers.

The data was collected in the Denver metropolitan area with a research proposal to interview passengers that was approved by the Colorado Multiple Institutional Review Board (COMIRB Protocol 16-0773, Exception APP001-3). The Denver metropolitan region includes a variety of contexts, covering both urban and suburban areas. This diversity of characteristics (e.g., density, race diversity, income 
levels, etc.) makes the Denver region a good place to study ride-hailing. Our sample is also random by design since the driver-author did not know where each ride would end up; this entailed driving all over the study area and providing transportation to passengers across a wide variety of socio-economic and socio-demographic characteristics. The only location that we had control over is where the app was turned on at the beginning of the shift. Thus, we varied the starting location from urban to suburban areas across the metropolitan region. We conducted all the data collection ourselves to eliminate bias between drivers, to control travel without a passenger (i.e., deadheading minimization), to reduce surveyor errors, and to ensure data quality.

For data collection, we used a sedan vehicle (2015 Honda Civic) and a smartphone (iPhone 5s). The main apps in the smartphone used for this research were "Lyft," "Uber-driver Partner," "GoogleMaps," and "My Tracks" (Figure 1). GoogleMaps and MyTracks GPS apps helped tracking and recording ridehailing travel data. For the origin and destination locations, we collected the closest cross streets, rather than the actual address, to maintain confidentiality. Driving shifts ranged from as low as two hours to as high as nine hours. All seven days and most times were covered during the study period, but a higher number of rides came during high demand times such as Friday and Saturday nights, representing typical ride-hailing services.
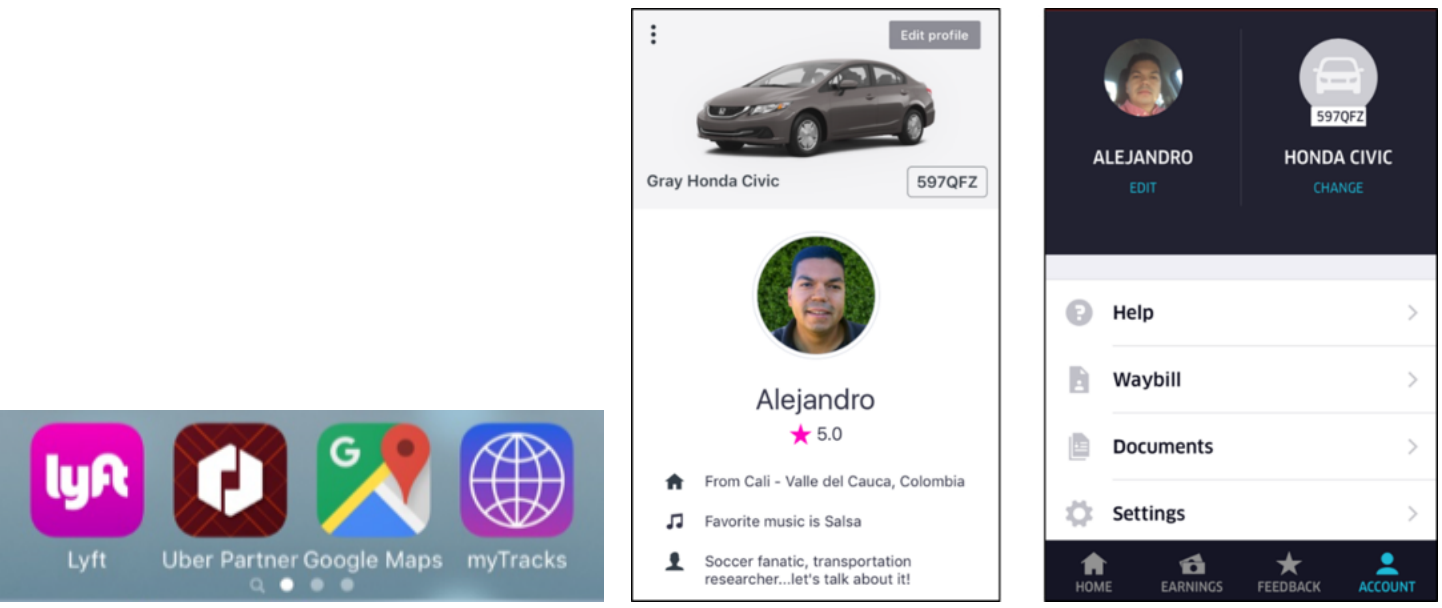

Figure 1. Lyft and Uber driver profiles and smartphone apps

We ended up with two inter-connected datasets: i) the ride-hailing driver dataset; and ii) the ridehailing passenger dataset. The first is the exclusive data that Uber/Lyft drivers can obtain by giving rides to passengers. This "driver dataset" contains information with GPS tracking of date, time of day, travel times, and travel distance (e.g., origin-destination rides). We also collected additional data relevant to parking, including the cost, time, and distance it would take to find a parking space after passenger dropoff. We based the parking location as a combination of different passenger rationalities (e.g., free parking, on-street metered parking, and garage parking in special destinations such as stadiums or airports). We recorded the cruising to park time and distance using the same GPS-based methodology. For the walking time and distance to final destination, we input the coordinate locations for parking and final destination (i.e., ride-hailing passenger drop-off) in Google Maps and recorded the estimated walking time and distance. We then described the destination type as high urban (e.g., central business district or CBD), general urban, suburban, or special event (e.g., airport, university campus, or stadium).

The "passenger dataset" contains information gathered by surveying passengers during the actual rides. On a typical day, the driver-author turned on both ride-hailing apps and waited until a passenger 
requested a ride. Once a passenger was on board during the ride, he/she was invited to participate in a short survey about ride-hailing both verbally and with signs in the car that read:

"Hi rider, I am a grad student doing research on transportation. Would you help me by doing a short survey ( -6 minutes) about this ride? You can use my tablet or go to this link www.ride-survey.com. Thank you!"

As the sign indicated, passengers had the option to take the survey using their own device or via a tablet device that was provided. In some cases, the driver-author conducted verbal interviews. Once the ride ended at the destination location, the other app was turned on to wait for a new passenger request. Once the passenger left the car, the driver-author tried to find the closest parking space available with the intent to minimize cruising distance without a passenger.

The passenger survey included three groups of questions:

- Specific Trip Questions

The first section asks passengers questions regarding the specific Uber/Lyft ride and includes questions such as trip purpose, travel mode replacement, and reasons to shift from a previous mode.

- General Use Questions The second part of the survey covers broader questions about travel behavior in general such as modality resources (e.g., car ownership, transit pass, etc.), general ride-hailing use, frequency of use for different modes, travel behavior changes, and more general reasons.

- Demographic Questions

The third section of the survey includes questions regarding characteristics of the individual and household (i.e., socio-economic demographics).

Table 1 depicts the demographics of our ride-hailing passengers. Comparing the summary statistics of this study to the overall Denver population, our respondents show a close gender split, higher representation from younger adults (ages $18-34,+28.2 \%)$ that are single or never married $(+21.4 \%)$, of white race $(+15.3 \%)$, with mid household incomes $(\$ 46 \mathrm{~K}-\$ 60 \mathrm{~K},+10.5 \%)$, and higher education levels (some college or higher, $+12.1 \%$ ). In contrast, our respondents exhibited lower representation from older populations (age $55+,-22.3 \%)$, married $(-11.9 \%)$, of Hispanic or Latin race $(-17.9 \%)$, with lower incomes ( $\$ 30 \mathrm{~K}$ or less, $-15.6 \%$ ), and lower education levels (high school or less, $-12.1 \%)$ ). Our sample shows that $17.8 \%$ of passengers were visitors from out of town.

The existing literature suggests that ride-hailing (and carsharing) users do not usually represent the general population in terms of income, age, and ethnicity (Murphy, 2016; Rayle et al., 2016). The authors from these papers suggest that these services mostly serve certain populations. Although the ride-hailing passengers from our study similarly skewed towards certain demographics as compared to the overall Denver population, we had higher participation from some subgroups as compared to the existing literature. For example, age, income and education were better distributed across a wider range than found in previous studies. Different from previous studies - where researchers used intercept surveys at specific locations or online- our research has the advantage of being random by design since the passengers' destination location is unknown.

We collected data over a period of 14 weeks during fall 2016. Our dataset includes 311 responses over the course of 308 rides (during three rides, more than one passenger took the survey). The survey response rate was $87.5 \%$. 


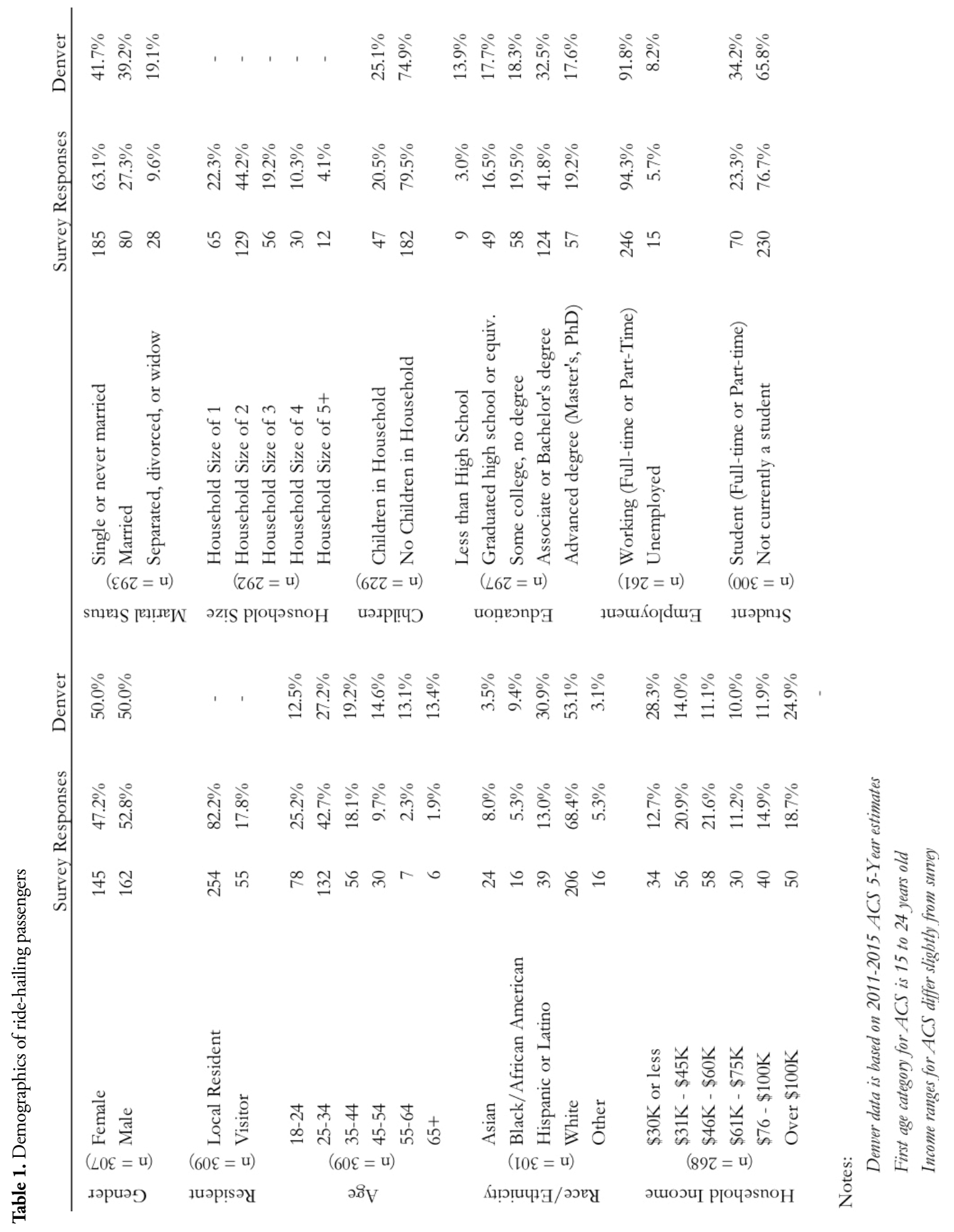




\section{$4 \quad$ Methods}

We examine the parking dataset using descriptive statistics and perform a one-way ANOVA test to analyze the difference in parking time means for three different groups. We then explore the relationship between parking time and parking cost for ride-hailing trips replacing driving. Lastly, we build a classification tree-based model to evaluate how ride-hailing influences parking demand (i.e., replacement of driving) and attempt to identify the variables that influence travel shifts.

\subsection{Tree-based model}

The classification tree-based model first assesses how mode replacement is affected from a set of variables in three areas: modality resources (e.g., car ownership), travel attributes (e.g., destination type, parking stress), and demographics (e.g., age). This analysis can help determine the level of importance and relationship between each variable and the outcome. The pruned categorical tree provides a visual representation with the categorical dependent variable at the root and the corresponding relative importance and associated threshold values at the top.

We used the classification and regression trees (CART) statistical method since it facilitated breaking down the predictor space into several regions based on the relationship of each group with the dependent variable of interest (Breiman, Friedman, Stone, \& Olshen, 1984). The model first groups the predictors using a specific method, such as simple average, and then it determines the true relation between the predictors, or covariates, and the variable of interest—ride-hailing replacing driving modes for this study - in each of the groups in the tree. Since our response variable is categorical, the model used for this study is called a classification tree-based model.

Finally, we "pruned" the tree to limit the size of the tree and avoid data over-fit by removing the least important splits based on deviance criterion and mean squared error. CART has the advantage of capturing and ordering the predictor variables based on relationship with the outcome while providing a graphical representation of these interactions. CART is used widely in several areas including environmental, construction, engineering, and computer science fields (Suchetana, Rajagopalan, \& Silverstein, 2017).

\subsubsection{Categorical dependent variable}

The dependent variable in the model is "mode being replaced by ride-hailing." We created categorical values based on answers to question Q5 (Figure 2) from the passenger survey: "For this trip, how would you have traveled if Lyft/Uber wasn't an option?" The survey response options to the multiple-choice question were then grouped into three categories: "replaced mode requiring parking," "replaced mode not requiring parking," or "new trip."

\subsubsection{Driver dataset predictors variables}

The following variables from the "driver dataset" were considered in the model:

- Parking time: continuous

- Parking cost: continuous

- Destination type: categorical (high urban, general urban, suburban, or special event) 


\subsubsection{Passenger dataset predictor variables}

The following variables from the "passenger dataset" were included in the model:

- Car ownership: binary (yes, no)

- Trip purpose: categorical (discrete, non-discrete, or airport)

- Parking as a reason to take ride-hailing instead of driving: binary (yes, no)

- Demographics: age (1 through 6 based on age levels), gender (male, female), income (1 through 6 based on levels)

We combined three of the parking variables (parking time, parking cost, and parking as a reason) to form a new predictor variable called "parking stress" with numerical levels from 0 to 4 . To do this, we first converted the three variables as follows:

- Parking time: if parking time was 0 , the new value is 0 ; if parking time was higher than 0 but lower or equal to 7 , the new value is 1 ; and if parking time was higher than 7 , the new value is 2 .

- Parking time: if parking cost was 0 , the new value is 0 ; otherwise, it is 1 .

- Parking as a reason: if parking as a reason was "no," the new value is 0 ; otherwise, it is 1 .

We used the statistical $\mathrm{R}$ program to perform our analysis, including the appropriate packages such as the "tree" and "prune.tree" packages that help fit categorical trees (Ripley, 2005). We started our model with the three categories previously described from the "mode replaced by ride-hailing" dependent variable using the specific trip dataset.

\section{$5 \quad$ Results}

This section is divided in four main subsections. First, we explore parking demand by analyzing driving trips being replaced with ride-hailing. Second, we assess parking as a reason to choose ride-hailing over other modes. These two subsections include results from the specific Uber/Lyft rides as well as the respondents' overall travel behavior. Third, we present results from the parking time and parking cost analysis. Lastly, we present results of the classification tree-based model.

\subsection{Parking demand}

To better understand how parking demand might be impacted by ride-hailing, we explored the driving trips that ride-hailing was replacing both for the specific origin to destination $(\mathrm{O}-\mathrm{D})$ ride and in a more general context.

\subsubsection{Parking demand: Specific trip}

Since vehicle parking, theoretically, is only needed for driving trips, we decided to look in more detail at the mode replacement distribution and pay close attention to the trips that would involve drivingsuch as drive alone or single occupancy vehicle (SOV), car rental, carpool (drive), and carsharing - to start understanding potential changes in parking demand.

In terms of replacing driving trips with ride-hailing, we should exercise some caution since, in some cases, the trip replaced might have been only a part of the trip with the intent to avoid parking at the destination. In other words, a passenger might have still driven and parked, but ride-hailing allowed him/ her to do so in a different location. For example, parking downtown might be limited and expensive, so a passenger decides to drive to a location —as close as possible to the destination-where parking is more abundant and/or free/cheaper. They then requested an Uber/Lyft ride to reach the final destination, thus benefiting from cost and time savings of a shorter ride-hailing trip. Within this section, we analyzed the specific ride with the question "For this trip, how would you have traveled if Uber/Lyft wasn't an op- 
tion?" under two conditions: i) the mode replaced is one of the driving options; and ii) driving is not part of a connection trip. Figure 2 illustrates that $26.4 \%$ of all respondents would otherwise have driven and needed a parking location.

\section{For this trip, how would you have traveled if Uber/Lyft wasn't an option?}

Driving (SOV, Car rental, Carsharing, Carpool)

Public transport

Wouldn't have traveled

Bike or Walk

Riding (Carpool, Get a ride)

Taxi

Other

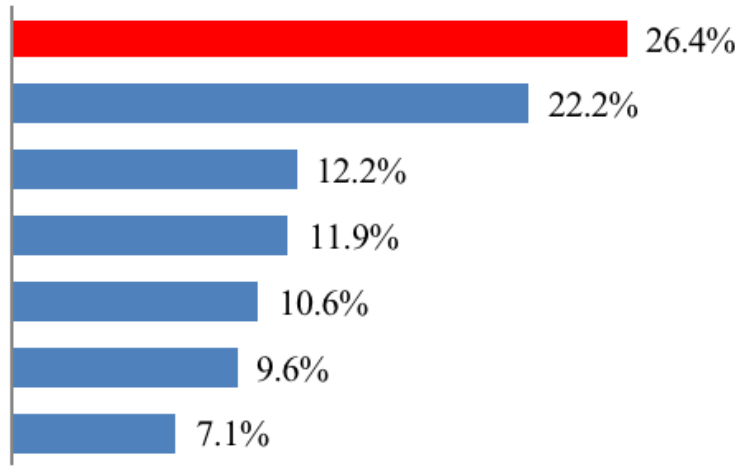

Figure 2. Ride-hailing replacing driving trips $(\mathrm{n}=311)$

Figure 3 represents the origin and destination locations for the specific ride-hailing trips. The outer circle represents the total of origins plus destinations; the corresponding color connecting one place over the other represents the ride-hailing trips originating at that location type. For example, the red color on the ring represents 32 total trips to/from restaurants, and the connections red lines represent 14 of the 32 originating there (keeping in mind that a few trips were from a restaurant/bar to another restaurant/bar). 


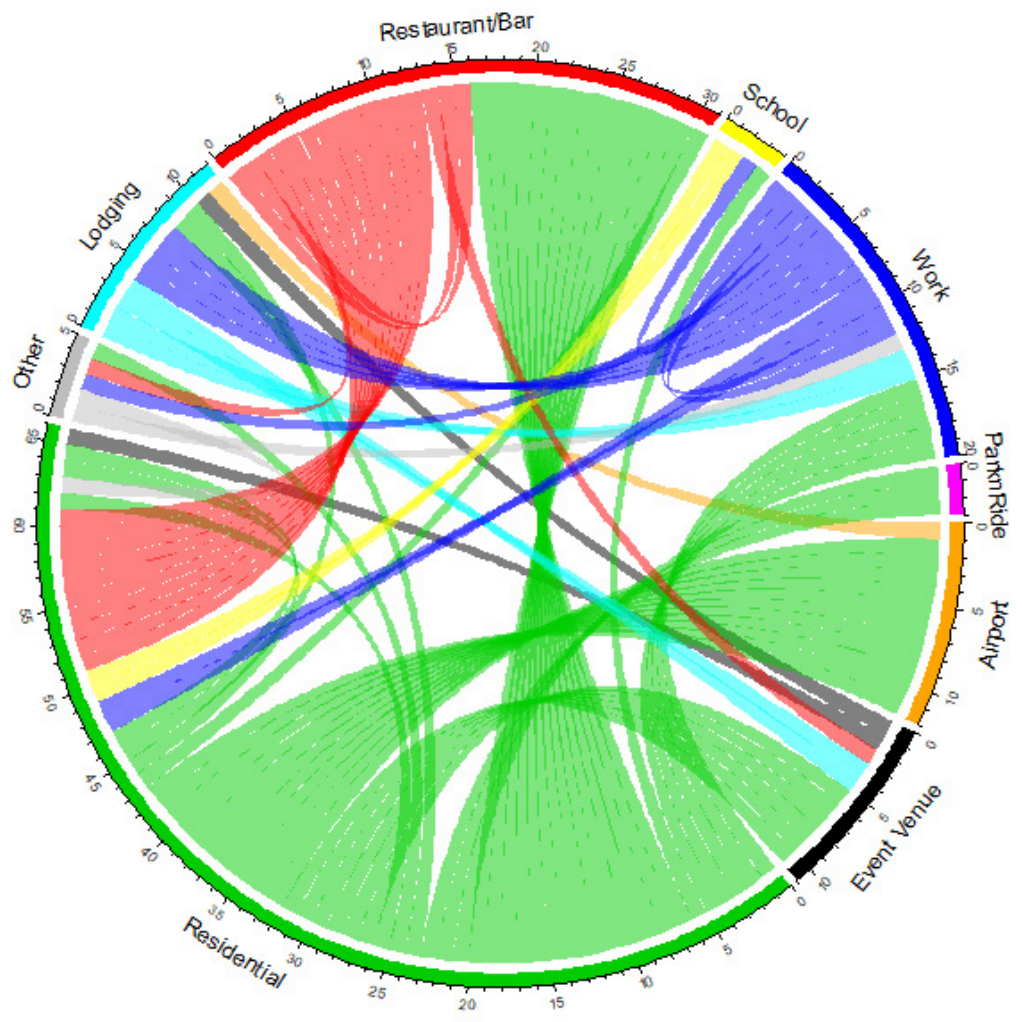

Figure 3. Origins and destination for ride-hailing replacing driving trips ( $\mathrm{n}=82$ to 82 )

\subsubsection{Parking demand: General use}

Beyond looking at the specific trips that would have needed parking, we considered the passengers' responses regarding travel behavior changes for different modes with the following sentence: "Complete the sentence based on your travel today compared to the past." The specific section of interest about parking is: "Because of ride-hailing, I drive..." with the response options: "a lot less," "a bit less," "about same," "a bit more," or "a lot more."

Figure 4 shows that about a third of participants stated that they drive less- $13.5 \%$ said a lot less and $19.0 \%$ said a bit less - which has implications for reduction in parking demand and slightly higher than the percentage of respondents to the specific trip replacement question. It was not expected that passengers would increase their driving, but $2.3 \%$ of respondents said, "a bit more" or a "lot more." Based on our experiences of interacting with passengers, this is explained as a handful of survey respondents are also ride-hailing drivers themselves. 


\section{Complete the sentence based on your travel today compared to the past. Because of ride-hailing, I drive...}

\begin{tabular}{|c|c|c|}
\hline A lot Less & $13.5 \%$ & \\
\hline A bit less & $19.0 \%$ & \\
\hline About the same & & $58.5 \%$ \\
\hline A bit more & $1.3 \%$ & \\
\hline A lot more & $1.0 \%$ & \\
\hline N.A. & $6.8 \%$ & \\
\hline
\end{tabular}

Figure 4. Ride-hailing and driving behavior change $(\mathrm{n}=311)$

\subsection{Parking difficulty as a reason to choose ride-hailing}

This subsection analyzes parking as a reason for someone to use ride-hailing over other modes of transportation, both for specific O-D ride-hailing trips and for general use.

\subsubsection{Parking difficulty: Specific trip}

Passengers stated the main reason that led them to choose Uber/Lyft over other options for their ride that day. Figure 5 presents the percentages for those passengers that "would have driven if ride-hailing was not available." "Parking" is highlighted in the responses as the second top reason in choosing ridehailing over driving.

For this trip, what is the main reason that led you to choose Lyft/Uber over other options?

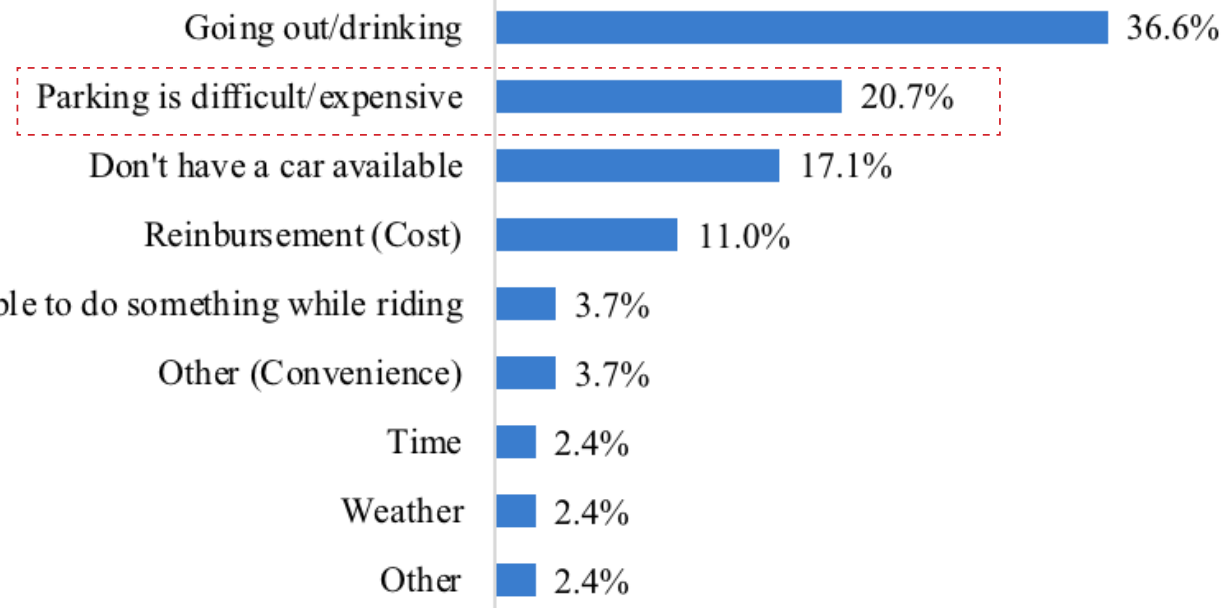

Figure 5: Percentage of "passengers that would have driven" identifying the main reason to choose ride-hailing $(\mathrm{n}=82)$ 
Exploring further on the type of trip including origin and destination locations, four out of five trips with a reason of going out and/or drinking was to an event venue (e.g., stadium), a restaurant, or a bar. For the trips stating parking as the main reason, about half were to the airport and a third again to an event venue, restaurant, or bar. Passengers responding "Don't have a car available" were travelers from out of town and passengers whose vehicle was getting repaired. Passengers stating that the cost of their ride-hailing trip would be reimbursed were either traveling to/from the airport or visitors from out of town.

\subsubsection{Parking difficulty: general use}

Complementing the main reason of using ride-hailing for the specific rides, we evaluated parking difficulty for the passengers' general travel behavior. We look specifically at the survey question: "In general, what are the main reasons you choose ride-hailing over other modes? (check up to three reasons)." About a third of respondents selected parking as one of the main reasons to use ride-hailing over other modes (Figure 6).

In general, what are the main reasons you chose ride-hailing over other modes? (check up to three reasons)

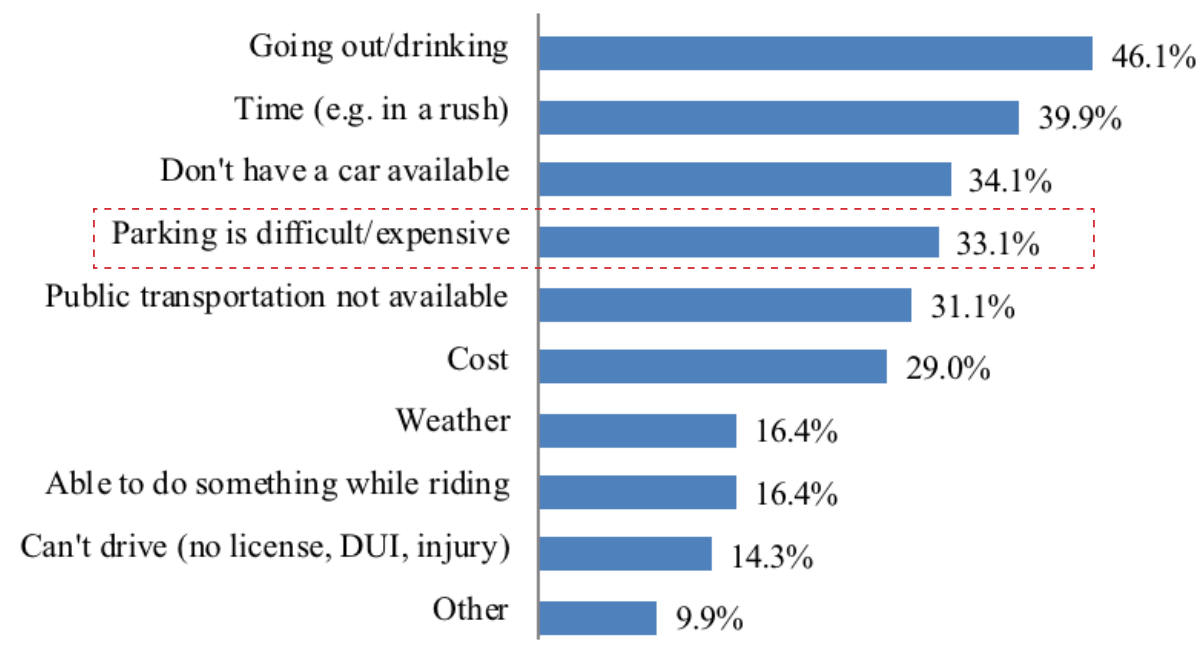

Figure 6. Percentage of all respondents identifying reasons to choose ride-hailing

Since parking is related to driving behavior, we examined the same dataset based upon the driving frequency of the passengers. To better understand the results, we selected the top five reasons from the dataset based on driving frequency, as shown in Table 2 . 
Table 2. Reasons to choose ride-hailing and driving frequency

\begin{tabular}{lccccc} 
& \multicolumn{5}{c}{ Driving Frequency } \\
\cline { 2 - 6 } Reasons to use ride-hailing & $\begin{array}{c}\text { Always } \\
\text { drive }\end{array}$ & Regularly Sometimes & Rarely & $\begin{array}{c}\text { Never } \\
\text { drive }\end{array}$ \\
\hline Going out, drinking & 68 & 28 & 17 & 7 & 15 \\
Parking is difficult & 46 & 27 & 14 & 5 & 5 \\
Time & 29 & 22 & 16 & 13 & 37 \\
Cost (including Reinbursement) & 31 & 19 & 7 & 5 & 25 \\
Don't have a car available & 29 & 13 & 8 & 13 & 36 \\
Able to do something while riding & 16 & 9 & 9 & 4 & 10 \\
Public transportation not available & 12 & 12 & 9 & 7 & 50 \\
\hline
\end{tabular}

In this table, we observe correlations between driving frequency and reasons choosing ride-hailing instead of the previous mode. High frequency drivers tend to use ride-hailing mostly when they are going out for social activities (i.e., avoid driving after drinking) and/or when they feel parking is difficult. Time-including travel savings and time use-while it was barely identified as a main reason for the specific trip (only 2.4\%, Figure 5), it was heavily cited on general behavior when choosing up to three reasons, thus acting as a secondary or complementary factor. Reasons such as cost (including reimbursement) and not having a car available (e.g., out of town travel, issues with the vehicle) — which were identified on previous specific trip analysis - were also mid-level indicators as to the general reasons why people shift from driving to ride-hailing. "Public transportation not being available" has low representation for high frequency drivers but was the most frequent reason cited by passengers that normally do not drive.

\subsection{Parking time, Parking cost, and time/cost relationships}

This subsection analyzes parking time, parking cost, and the relationship between time savings and cost for those passengers shifting from driving to ride-hailing. We first present descriptive statistics on these variables and then present results comparing cost and time for passengers shifting from driving to ridehailing with parking as the main reason.

\subsubsection{Parking times}

Table 3 presents summary statistics for the 311 observations on parking times including: i) cruising for parking, and ii) walking to final destination. For most rides, we experienced less than thirty seconds of additional times for parking and walking to the final destination, but the additional total time can be up to 29 minutes with a mean time of 3.4 minutes. 
Table 3. Parking time summary statistics (in minutes)

\begin{tabular}{lccc} 
& Cruising to Park & Walking to Destination & Additional Time for Parking \\
\hline Mean & 1.2 & 2.2 & 3.4 \\
St. Dev. & 2.0 & 4.3 & 6.1 \\
Min & 0.0 & 0.0 & 0.0 \\
Max & 11.0 & 20.0 & 29.0
\end{tabular}

Figure 7 presents the distribution of additional time for parking for those that took at least one minute. Most of the rides with a total of 15 or more minutes to park were experienced at Denver International Airport (DIA), university campus, or event venues (e.g., stadium, theater).

\section{Additional Parking Time}

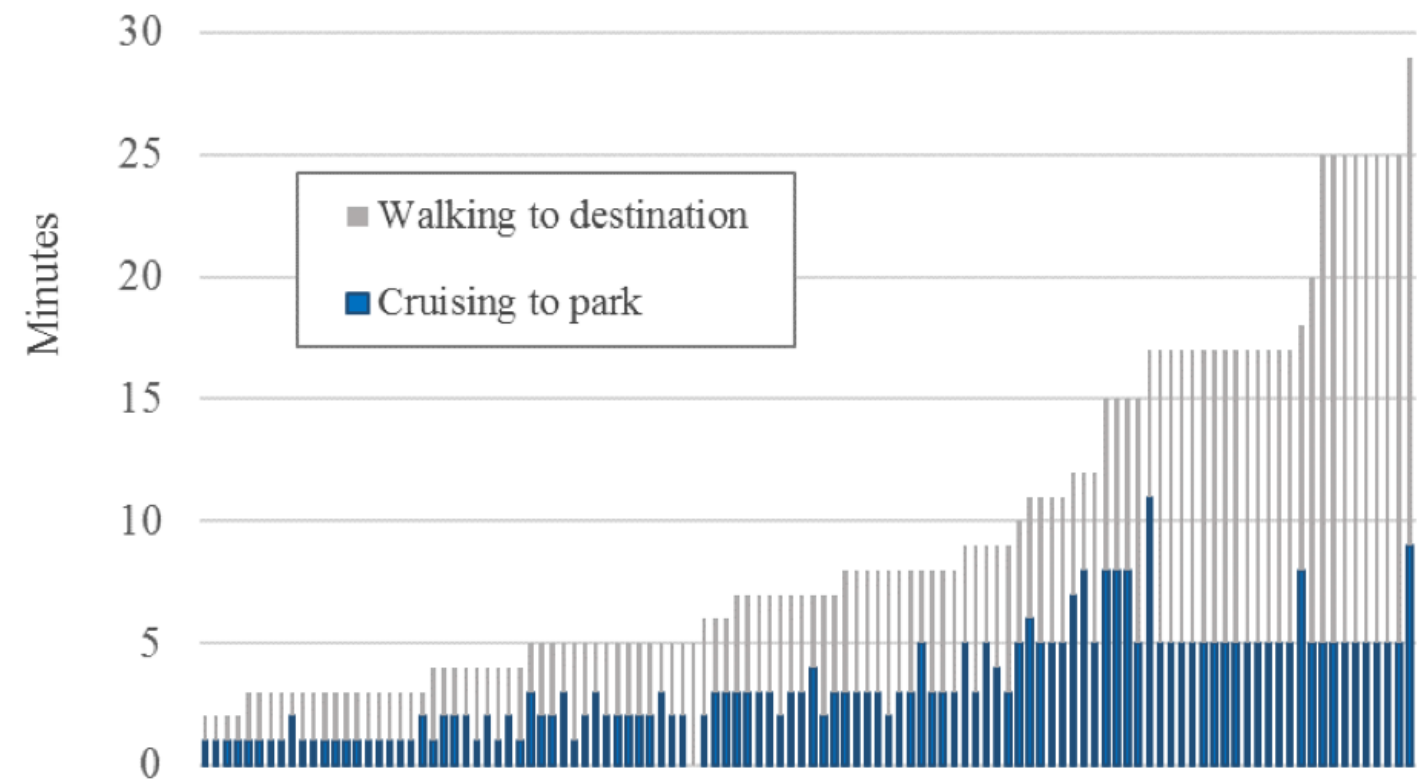

Figure 7. Additional parking time if driving

We use a one-way ANOVA test with post-hoc Tukey HSD to compare the "additional parking time if driving" mean of the three sub-groups based on the mode being replaced. The ANOVA results show a statistically significant difference in parking time for two out of the three sub-groups

The first post-hoc Tukey HDS compares the difference in the time it takes to park and walk to the destination for those stating they were replacing a driving trip and those stating they were replacing another mode, with a significant difference. Compared to "other mode" replaced, ride-hailing trips that replaced a driving trip would have taken, on average, 2.6 minutes longer to park and walk to the destination.

The second comparison looks at those stating they are replacing a driving trip against those stating they would not have taken the trip at all. This also results in a statistically significant difference of 3.8 minutes longer for those replacing the driving trip.

The last ANOVA, comparing those that stated they were replacing a mode other than driving against those that would not have taken the trip, did not result in a significant difference. 
Table 4. Tukey simultaneous tests for differences of means (Parking time per mode replaced)

\begin{tabular}{lccc} 
& $\begin{array}{r}\text { Parking Time } \\
\text { Difference }\end{array}$ & $95 \%$ C.I. & $\begin{array}{c}\text { Adjusted } \\
\text { p-value }\end{array}$ \\
\hline Replaced Driving vs. Replaced Other Mode & 2.61 & $(0.77,4.44)$ & $\mathbf{0 . 0 0 2 6}$ \\
Replaced Driving vs. Induced Trip & 3.80 & $(1.06,6.53)$ & $\mathbf{0 . 0 0 3 4}$ \\
Replaced Other Mode vs. Induced Trip & -1.19 & $(-3.68,1.30)$ & 0.4991
\end{tabular}

\subsubsection{Parking cost}

Parking cost was not high for most of the rides (Figure 8). High parking cost was only experienced at DIA, universities, special events (e.g., sports, concerts), and private parking in the CBD.

\section{Percent of all rides}

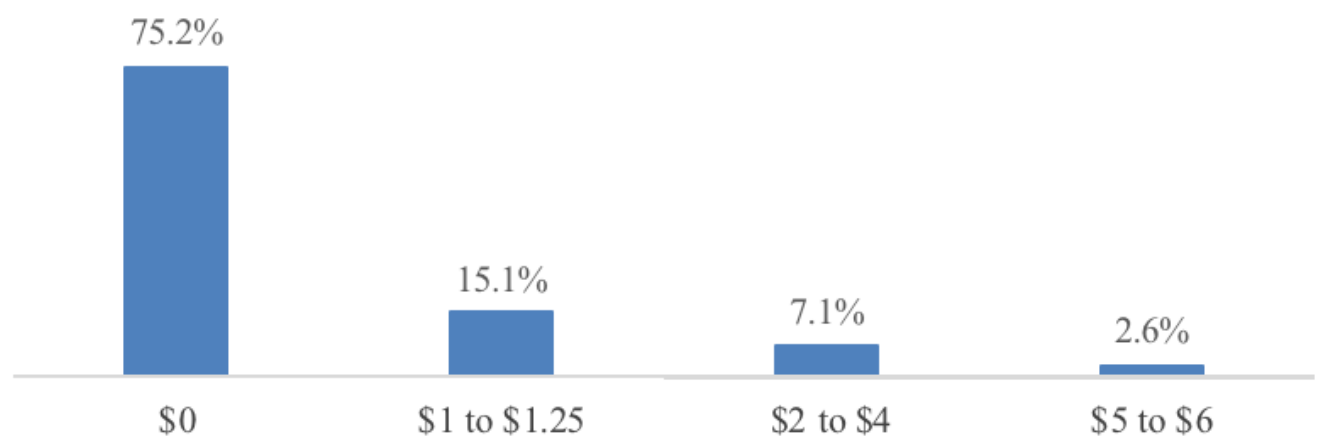

Figure 8. Parking cost

\subsubsection{Additional Monetary Cost and Time Gains: Willingness to pay for parking?}

When passengers shift from mode A to mode B, they gain and lose certain utility. Since time and cost are two of the most important predictors on mode choice, we decided to evaluate these two variables for the trips that would have been by car. We use travel times and cost for ride-hailing rides versus hypothetical driving trips. We exclude trips where passengers stated a strong reason and would have unbalanced the results; these include going out/drinking, visitors not having a car available, and trips to the airport (since many trips can be travel reimbursed and we did not have information on how long passengers were going to be out of town to determine total parking cost). For ride-hailing travel time, we use data collected on waiting for ride-hailing plus on-board time; for driving travel times, we use driving time plus parking times. For cost, we have detailed information on total ride-hailing fare; for driving, we estimate cost per mile driven, using $\$ 0.54$ per mile based on the U.S. Federal standard mileage rate in 2016, summed with parking cost. Assuming unbiased decision-making, we would expect to see little shift from driving to ride-hailing when parking time and parking cost is low; on the other hand, we would expect to see large shifts when parking time and parking cost is high. If parking time and parking cost are going in different directions, then we are uncertain. Figure 9 presents boxplots comparing travel time and cost for driving versus ride-hailing for trips shifting from driving to ride-hailing, showing that passengers pay more to save time. While all travel times are not the same (e.g., driving time, on-board time, waiting time, and/or parking time), these results might give us insight into the potential expense passengers are willing to pay to save parking time. 


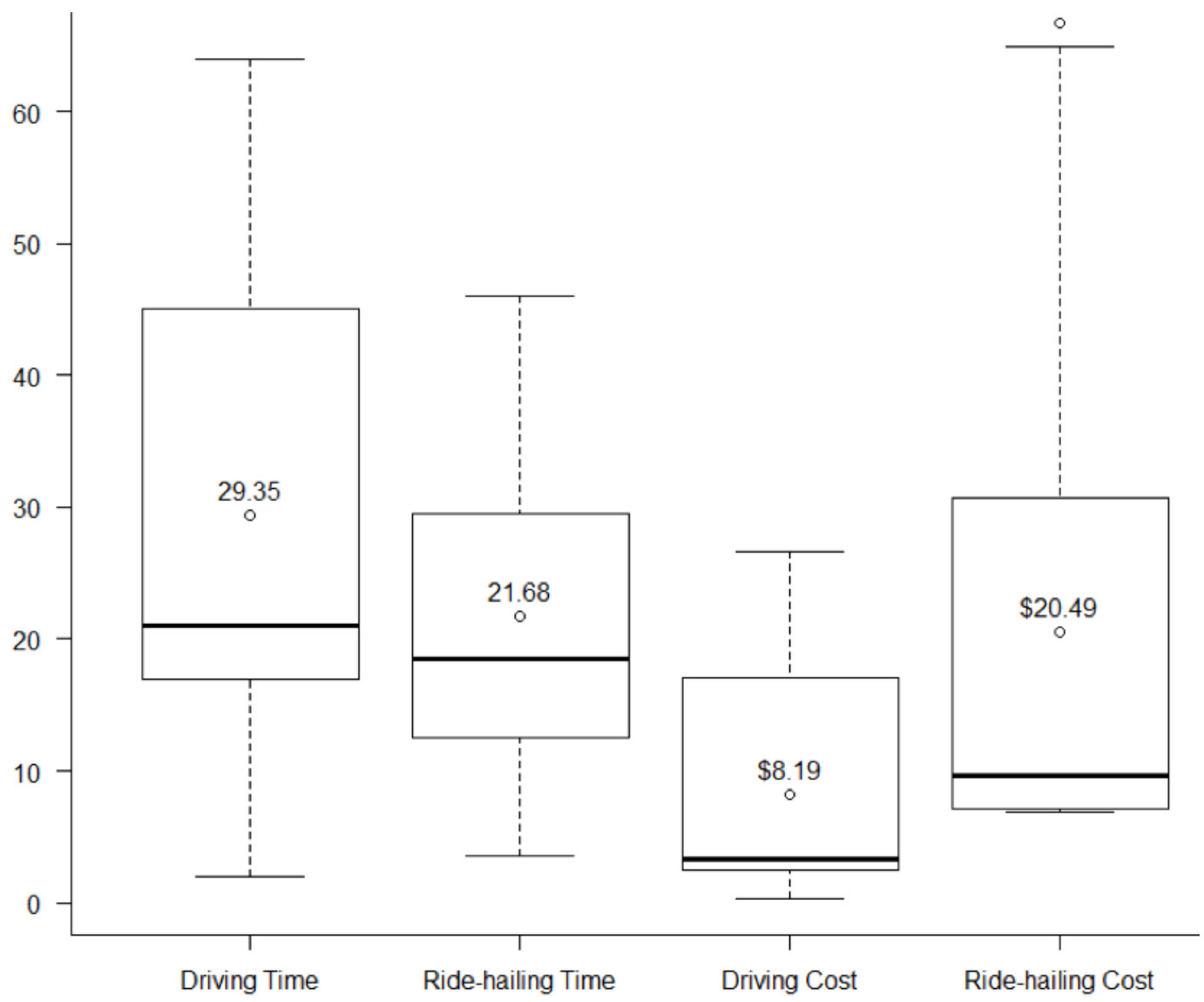

Figure 9. Travel times and monetary cost, ride-hailing over driving $(\mathrm{n}=17)$

\subsection{Tree-based model}

The final tree-based model includes the dependent variables "mode replacing parking" as a binary "yes" or "no" and the following five predictors: "car ownership (car)"; "destination type (destype)"; "parking stress (pstress)"; "age (age)"; and "gender (gender)." The age ordinal value is distributed as follows: 1 for "18 to 24 years old"; 2 for " 25 to 34 years old"; 3 for "35 to 44 years old"; and 4 for " 45 years old or older." Figure 10 presents the visual representation of the best classification tree-based model after pruning the tree. 


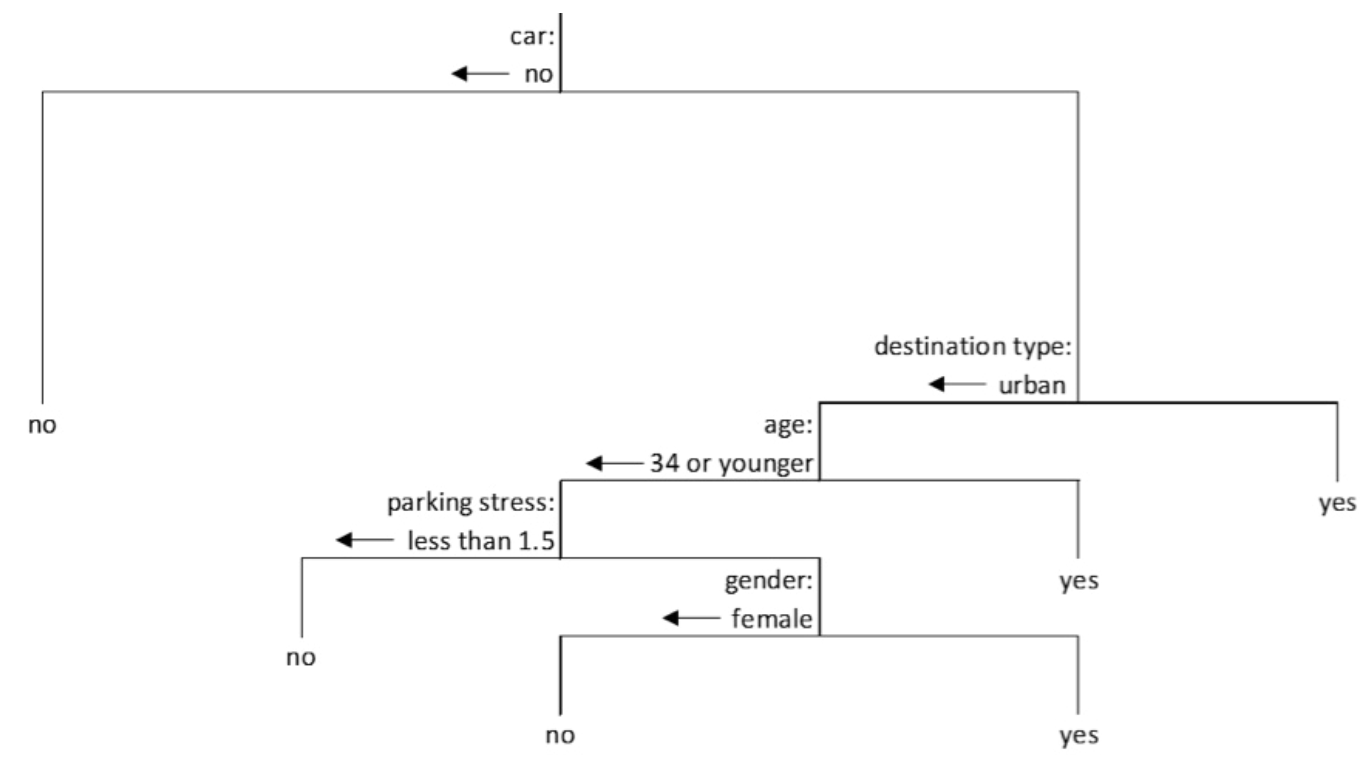

Figure 10. Best classification tree model of ride-hailing replacing modes requiring parking with car ownership, destination type, stress level, age, and gender

The final prune tree contains 268 observations of five variables with six nodes, and a model accuracy of 0.74 . The highest-level predictor is whether a passenger owns a car or not. For those passengers not owning a car, the mode replaced is non-driving (e.g., transit, walking, or biking). Destination type is the second level predictor, showing, for example, that a person owning a car and going to a suburban or special destination would have driven. Following car ownership and destination type is age. If a person owns a car, is going to an urban place, and is 35 years old or older, they are most likely to drive. However, if they are 34 or younger, it would depend on our fourth and fifth predictors: parking stress and gender. For female passengers that are 34 years old or younger, own a car, and are going to an urban destination, a parking stress level of 2 or more might represent the reason why they would take ride-hailing instead of driving.

This model helps shed light on driving trips being replaced by ride-hailing-particularly with respect to the subsequent parking issues—and the relationship with the predictors. Take, for example, a passenger data subset in which passengers answer: "Do you (or your household) own fewer cars because of ride-hailing?" For the 311 passengers surveyed, $12.5 \%$, or 39 people, stated yes. Of those 39 passengers, 18 still had access to a car. Our tree-based model predicts 13 driving trips replaced $33.3 \%$ of the 39 passenger). If all those 39 passengers would have had access to a car, our model would have predicted 25 replaced driving trips (64.1\% of the 39 passengers).

\subsection{Discussion and conclusions}

Emerging transportation services such as ride-hailing might be creating a window of opportunity to help dissolve individualized car-dependency and the transportation infrastructure centered around this pattern, particularly parking. Thus, this study aims to investigate the reciprocal influence of an evolving transportation service — ride-hailing — in terms of a very important transportation topic — parking — so we can better model, design, and build future infrastructure.

First, we look at parking demand by analyzing the transportation modes being replaced by Lyft/ Uber. Results suggest that $26.4 \%$ of Uber/Lyft riders would have driven and needed a parking space if these ride-hailing services did not exist. Also, about a third of respondents stated that they are driving 
less when asked about general travel behavior. The most common places for ride-hailing replacing driving trips are restaurant/bars, working trips to the CBD, airport, lodging, and event venues. Second, we analyzed parking as a stated reason for using ride-hailing, showing that for both the specific surveyed trip as well as with their more general usage, parking difficulty (e.g., availability, additional time, and cost) is the second most cited reason for trips replacing driving. We then investigated the relationship between parking time and parking cost. While time spent and monetary cost between driving versus ride-hailing is not exclusively parking-related, we were able to analyze in more detail the rides where passengers stated parking as the main reason, excluding trips that might bias the decision. When individually considering the costs of driving and ride-hailing, we found that passengers, on average, spent more money on a ridehailing trip that would not necessitate cruising for parking and walking to the final destination. This could provide insight into right pricing parking structures to better manage parking demand and supply, which would in turn, increase the traveler experience without inducing negative externalities. Finally, we presented the best fit classification tree-model with our data, showing that car ownership, destination type, parking stress level, age, and gender are factors contributing to reducing the modes requiring parking with the use of ride-hailing services. Trip purpose and income were not significant in our model.

When passengers shift away from driving, cities might gain space from people not needing to park, but they still need to manage where and how people get pick-up/drop off with ride-hailing. Besides passengers, they need to manage ride-hailing drivers (including parking for ride-hailing drivers). The experience as a ride-hailing driver shows that passenger pick-up/drop-off can be stressful with safety concerns, customer experience, and drivers/passengers being able to find each other. Stress is higher when the origin or destination is in dense urban areas such as the $\mathrm{CBD}$ and/or places at university campuses/ stadiums that do not provide adequate curb space. For example, during some rides, passengers wanted to get out of the car in areas that could compromise their own safety or the safety of others (e.g., wanting to get off at the bike lane, at a red light, etc.). On one hand, drivers want to do the right thing and not allow passengers to dangerously disembark; on the other hand, they know that passengers could get upset if they were not allowed to leave and then give a bad rating. Proper infrastructure and communication between city enforcement and ride-hailing companies could alleviate some of these issues.

The main limitation of our study is the trip sample size relative to the overall number of rides that Uber and Lyft provide. Another limitation is that our case study focuses on Denver and the surrounding areas and might not be applicable to other metropolitan regions. Despite our study limitations, we learned many lessons for future research. For example, ride-hailing is very dynamic and could provide different infrastructure use at different times (e.g., parking during the day, and pick-up/drop-off at night). Further exploration on travel cost and travel times is very important for mode choice, including different values for separate travel times (waiting, on-board, driving, parking). Other future potential research include value on curb space access to incentivize sharing/carpool behaviors and/or willingness to pay for riding alone; and parking needs for ride-hailing drivers based on driving strategy in-between rides (park and wait, travel to places with potentially high demand and wait, cruise around)

While total taxi and ride-hailing passenger miles in the U.S. is less than one percent of total vehicle miles traveled (U.S. Department of Transportation, 2017), the percentage is much higher for specific destinations in urban areas such as restaurant/bars, airports, CBD, lodging, event venues. With this study, we find evidence that cities might want to examine transportation infrastructure (e.g., parking, ride-hailing pick-ups/drop-off space or PUDOs, built environment that encourages other non-vehicular modes) and adaptation strategies (e.g., pricing to deal with supply and demand) to provide a better travel experience for all and aiming at specific city goals (e.g., increase walking, biking, and public transit use, and/or higher vehicle occupancy). Similarly, parking requirements and parking supply for specific developments such as bars, restaurants, event venues, and airports should be re-evaluated so that we can design buildings with lower parking capacity in the future. 


\section{Acknowledgements}

The work presented in this paper was conducted with support from the University of Colorado Denver and the Mountain-Plains Consortium, a University Transportation Center funded by the U.S. Department of Transportation. We would also like to express our gratitude to the National Science Foundation for providing funding through the Bridge to the Doctorate Program and the U.S. Department of Transportation for the Dwight D. Eisenhower Graduate Fellowship. 


\section{References}

Breiman, L., Friedman, J., Stone, C. J., \& Olshen, R. A. (1984). Classification and regression trees. Boca Raton, FL: CRC press.

Brewer, J. (2000). Ethnography. New York: McGraw-Hill Education.

Brooke, S., Ison, S., \& Quddus, M. (2014). On-street parking search. Transportation Research Record: Journal of the Transportation Research Board, 2469, 65-75.

Clewlow, R. R., \& Mishra, G. S. (2017). Disruptive transportation: The adoption, utilization, and impacts of ride-hailing in the United States. Retrieved from https://trid.trb.org/view/1485471

Guo, Z. (2013). Does residential parking supply affect household car ownership? The case of New York City. Journal of Transport Geography, 26, 18-28. doi.org/10.1016/j.jtrangeo.2012.08.006

Hampshire, R. C., Simek, C., Fabusuyi, T., Di, X., \& Chen, X. (2017). Measuring the impact of an unanticipated suspension of ride-sourcing in Austin, Texas. Retrieved from https://papers.ssrn.com/ sol3/papers.cfm?abstract_id=2977969

Henao, A. (2017). Impacts of ridesourcing — Lyft and Uber —on transportation including VMT, mode replacement, parking, and travel behavior. Denver: University of Colorado at Denver.

Henao, A., \& Marshall, W. E. (2018). The impact of ride-hailing on vehicle miles traveled. Transportation. doi.org/10.1007/s1111

Henao, A., Sperling, J., Garikapati, V., Hou, Y., \& Young, S. E. (2018). Airport analyses informing new mobility shifts: Opportunities to adapt energy-efficient mobility services and infrastructure. Paper presented at the Intelligent Transportation Society of America, Detroit. National Renewable Energy Lab. NREL/CP-5400-71036. Retrieved from https://www.nrel.gov/docs/fy18osti/71036.pdf

Hess, D. (2001). Effect of free parking on commuter mode choice: Evidence from travel diary data. Transportation Research Record: Journal of the Transportation Research Board, 1753, 35-42.

Lewis, S. (2015). Qualitative inquiry and research design: Choosing among five approaches. Health Promotion Practice, 16(4), 473-475.

Mandle, P., \& Box, S. (2017). Transportation network companies: Challenges and opportunities for airport operators. Washington, DC: The National Academies Press.

Morris, D. Z. (2018, February 24). Yes, Uber really is killing the parking business. Fortune. Retrieved from http://fortune.com/2018/02/24/yes-uber-really-is-killing-the-parking-business/

O’Reilly, K. (2012). Ethnographic methods. London: Routledge.

Rayle, L., Dai, D., Chan, N., Cervero, R., \& Shaheen, S. (2016). Just a better taxi? A survey-based comparison of taxis, transit, and ridesourcing services in San Francisco. Transport Policy, 45, 168-178. doi.org/10.1016/j.tranpol.2015.10.004

Ripley, B. (2005). Tree: Classification and regression trees. R package version, 1.0-19.

Shoup, D. C. (2006). Cruising for parking. Transport Policy, 13(6), 479-486. doi.org/10.1016/j.tranpol.2006.05.005

Steele, J. (2018, February 22). Ace Parking says Uber, Lyft have cut parking business up to $50 \%$ in some venues. The San Diego Union Tribune. Retrieved from http://www.sandiegouniontribune.com/business/growth-development/sd-fi-ace-parking-uber-lyft-competition-20180222-story.html

Suchetana, B., Rajagopalan, B., \& Silverstein, J. (2017). Assessment of wastewater treatment facility compliance with decreasing ammonia discharge limits using a regression tree model. Science of The Total Environment, 598, 249-257.

U.S. Department of Transportation, FHA. (2017). 2017 National Household Travel Survey. Retrieved from https://nhts.ornl.gov

Vaccaro, A. (2016, December 05). Highly touted Boston-Uber partnership has not lived up to hype so 
far. Boston.com. Retrieved from http://www.boston.com/news/business/2016/06/16/bostons-uberpartnership-has-not-lived-up-to-promise

Weinberger, R. (2012). Death by a thousand curb-cuts: Evidence on the effect of minimum parking requirements on the choice to drive. Transport Policy, 20, 93-102. doi.org/10.1016/j.tranpol.2011.08.002

Weinberger, R., Seaman, M., \& Johnson, C. (2009). Residential off-street parking impacts on car ownership, vehicle miles traveled, and related carbon emissions. Transportation Research Record: Journal of the Transportation Research Board, 2118, 24-30.

Wilson, R. W., \& Shoup, D. C. (1990). Parking subsidies and travel choices: Assessing the evidence. Transportation, 17(2), 141-157.

Wilson, R. W. (1992). Estimating the travel and parking demand effects of employer-paid parking. Regional Science and Urban Economics, 22(1), 133-145. doi.org/10.1016/0166-0462(92)90029-Z

Zipkin, A. (2017, December 11). Airports are losing money as ride-hailing services grow. NY Times. Retrieved from https://www.nytimes.com/2017/12/11/business/airports-ride-hailing-services.html 